\title{
Penanganan Keluhan Tamu dengan Metode ILEAD Oleh Karyawan Kantor Depan di Hotel Holiday Inn Resort Baruna Bali
}

\author{
I Kadek Ngurah Sukamerta, Nyoman Dini Andiani
}

\section{Undiksha}

\begin{abstract}
Abstrak
Strategi penanganan keluhan tamu sangat penting untuk ditingkatkatkan karena mampu menciptakan kualitas pelayanan serta hubungan kerja sama yang baik kepada tamu. Penelitian ini merupakan penelitian kualitatif dengan analisis deskriptif. Tujuan dari penelitian ini untuk mengetahui Strategi Penanganan Keluhan yang dilakukan oleh karyawan Kantor Depan di Hotel Holiday Inn Resort Baruna Bali. Data yang diperoleh merupakan data primer yang didapat dari hasil wawancara kepada Manajer Kantor Depan. Hasil penelitian menunjukan bahwa Penangana Keluhan yang dilakukan oleh karyawan kantor depan di hotel holiday inn resort baruna bali menggunakan metode ILEAD yaitu Identify, Listen, Empathize, Apologize,dan Deliver Solution. Metode ILEAD sebagai strategi penanganan keluhan sudah berjalan dengan baik.
\end{abstract}

Kata kunci: Manajemen Strategi, Keluhan Wisatawan, Kepuasaan Wisatawan, Kantor Depan

The strategy for handling guest complaints is very important to be improved because it is able to create quality service and a good cooperative relationship with guests. This research is a qualitative research with descriptive analysis. The purpose of this study was to determine the Complaints Handling Strategy conducted by Front Office employees at the Holiday Inn Resort Baruna Bali Hotel. The data obtained are primary data obtained from interviews with Front Office Managers. The results showed that the Complaints Handling conducted by front office employees at the Baruna Bali Holiday Inn Resort used the ILEAD method, namely Identify, Listen, Empathize, Apologize, and Deliver Solution. The ILEAD method as a complaint handling strategy has been running well.

Keywords: Strategy Management, Tourist Complaints, Tourist Satisfaction, Front Office.

\section{Pendahululuan}

Hotel merupakan salah satu akomodasi yang menyediakan pelayanan bagi masyarakat umum dengan fasilitas jasa penginapan, penyedia makanan dan minuman, jasa pelayanan kamar dan jasa pencucian pakaian. Dalam menjalin hubungan kerjasama yang berkelanjutan antara perusahaan dengan wisatawan, perusahaan dituntut untuk mampu memberikan pelayanan yang berkualitas dan dapat memenuhi segala kebutuhan pelanggan sehingga nantinya tamu atau wisatawan akan melakukan kunjungan kembali (Guest Refeater).

Pada umumnya sebagian besar perusahaan pada bidang pariwisata dan non pariwisata yang menyediakan jasa pelayanan kepada tamu tidak pernah lepas dari perilaku keluhan wisatawan (Customer Complaint). Keluhan biasanya terjadi karena banyaknya 
JMPP, Vol 3 No 1, April 2020

p-ISSN: 2654-9719

insan perusahaan yang belum memahami tentang perilaku wisatawan dan kepuasan wisatawan, yang berkaitan dengan apa yang dibutuhkan, dan yang diinginkan oleh konsumen. Beberapa perusahaan memilih untuk menerapkan strategi sendiri bagi perusahaan mereka. Keluhan tamu biasanya terjadi pada bagian Kantor Depan dikarenakan pada seksi tersebut merupakan kesan pertama tamu ketika tiba pada sebuah hotel.

Strategi penanganan keluhan yang dapat dilakukan oleh karyawan Kantor Depan di Hotel Holiday Inn Resort Baruna Bali dalam menangani keluhan tamu yaitu dengan menggunakan metode ILEAD. Berdasarkan dari latar belakang tersebut dapat simpulkan bahwa tujuan dari penelitian ini adalah membahas lebih lanjut tentang penanganan keluhan tamu menggunakan metode ILEAD pada bagian Kantor Depan di Hotel Holiday Inn Resort Baruna Bali.

\section{KajianPustaka}

\subsection{Konsep Tentang Manajemen Strategi}

Strategi merupakan suatu ilmu yang dirancang dengan memanfaatkan sumber daya manusia dan memiliki dampak, serta pengaruh yang besar bagi keberlangsungan perusahaan. Menurut Surjani (2002:21), Manajemen strategi dapat diartikan sebagai gabungan antara seni dan ilmu dalam hal menyusun, menerapkan dan menilai keputusankeputusan lintas fungsi, yang memungkinkan suatu organisasi untuk mencapai tujuannya di masa yang akan datang.

Manajemen strategi adalah serangkaian keputusan dan tindakan mendasar yang dibuat oleh manajemen puncak dan diterapkan oleh seluruh insan suatu organisasi untuk mencapai tujuan organisasi tersebut (Siagian, 1998, dalam Chaniago, 2014:87).

\subsection{Kajian Tentang Keluhan Wisatawan}

Keluhan merupakan hal yang biasa diutarakan oleh para konsumen setelah mereka mengalami ketidaksesuaian atas jasa yang telah diberikan (Sitanggang, 2017:16). Menurut Bell dan Ludington (2006, dalam Tarigan, 2018:40), "umpan balik keluhan pelanggan atau feedback biasanya dilakukan melalui lisan maupun tulisan"

Menurut Collier (2012) strategi penanganan keluhan dapat menggunakan metode ILEAD yaitu Identify, Listen, Empathize, Apologize dan Decide.

\subsection{Tinjauan Tentang Kepuasan Wisatawan}

Pada dasarnya kepuasan pelanggan merupakan suatu ungkapan dan evaluasi pelanggan terhadap kualitas produk atau jasa yang ditawarkan. Menurut Kotler (2000, dalam Kalebos, 2016:493), Kepuasan Pelanggan adalah tingkat perasaan seseorang 
JMPP, Vol 3 No 1, April 2020

p-ISSN: 2654-9719

setelah membandingkan kinerja atau hasil yang dirasakan rasakan dan dibandingkan dengan ekspektasinya.

\subsection{Konsep Kantor Depan}

Kantor depan merupakan kesan pertama dan terakhir tamu. Artinya ketika tamu ingin melakukan check in, check out, keluhan (complaint), dan atau menanyakan informasi, yang pertama mereka datangi adalah kantor depan. Oleh sebab itu, penilaian tentang keseluruhan hotel lebh cenderung dilihat dari kualitas pelayanan kantor depan.

Menurut Bagyono (dalam Kisti \& Mayasari. 2019:78) fungsi departemen kantor depan adalah, sebagai berikut :

1. Menjual kamar (reservation, check-in, check-out)

2. Menangani informasi produk/ pelayanan dan informasi umum di luar

3. Mengkoordinasi pelayanan tamu dengan departemen lain

4. Melaporkan status kamar

5. Mencatat pembayaran tamu (guest folio)

6. Menyelesaikan pembayaran tamu pada saat tamu check out

7. Menyusun riwayat kunjungan tamu untuk tujuan peningkatan pelayanan

8. Menangani telepon, pesan, faximili dan email

9. Menangani barang bawaan tamu

\section{Metodelogi Penelitian}

Penelitian ini merupakan penelitian kualitatif dengan analisis deskriptif yaitu Data yang diperoleh akan diolah dengan analisis deskriptif kualitatif, sehingga didapat penarikan kesimpulan secara deskriptif. Tehnik pengumpulan data menggunakan metode wawancara tertulis, observasi dan dokumentasi. Jenis data yang digunakan pada penelitian ini adalah data primer. Narasumber pada penelitian ini adalah bapak Aries Susanto selaku Manajer Kantor Depan di Hotel Holiday Inn Resort Baruna Bali.

\section{Hasil Penelitian dan Pembahasan}

\subsection{Strategi Penanganan Keluhan Wisatawan di Bagian Kantor Depan, Hotel Holiday Inn Resort Baruna Bali}

Berdasarkan dari hasil wawancara tertulis pada tanggal 29 Mei 2020, kepada bapak Aries Susanto, selaku Front Office Manajer di Hotel holiday Inn Resort Baruna Bali, yang memberikan penjelasan bahwa strategi penanganan keluhan menggunakan metode ILEAD: Identify, Listen, Empathize, Apologize, Deliver Solution.

1. Identify

Hal pertama yang dilakukan oleh karyawan kantor depan dalam menangani keluhan Jurnal Manajemen Perhotelan dan Pariwisata | 38 
tamu adalah melakukan identifikasi masalah tentang hal-hal apa saja yang membuat tamu tersebut merasa kurang nyaman. Dalam hal ini karyawan kantor depan harus teliti dan cermat dalam mencari inti permasalahn yang muncul. Hal yang dapat dilakukan yaitu mengajukan pertanyaan seperti apa permasalahn yang dihadapi.

2. Listen

Tahap kedua yang dilakukan adalah mendengarkan dengan seksama penjelasan yang diberikan oleh tamu dan tetap menjaga kontak mata dengan tamu. Dalam hal ini karyawan kantor depan harus tetap tenang, tanpa emosi, serta tetap mencari poin permasalahan. Hal-hal yang dapat dilakukan adalah menulis inti permasalahan serta mengulangi kembali inti permasalahan tersebut kepada tamu.

\section{Empathize}

Tahap ke tiga adalah seorang karyawan kantor depan harus mampu memahami kondisi dan tingkat emosional tamu serta menunjukan sikap empati atau ikut merasakan atas apa yangdirasakan tamu tersebut. Dalam hal ini karyawan kantor depan harus menunjukan rasa peduli atas permasalahn yang dialami oleh tamu tersebut.

\section{Apologize}

Tahap ke empat yaitu seorang kayrawan kantor depan harus mengajukan permintaan maaf atas ketidaknyamanan yang terjadi. Dalam hal ini permintaan maaf harus disampaikan dengan alasan yang logis dan nada bicara yang sopa, sehingga tamu dapat memahami situasi dan kondisi yang terjadi.

5. Deliver Solution

Tahap trakhir yaitu memberikan solusi atas permasalahan yang terjadi. Dalam hal itu harus terdapat persetujuan dari pihak manajemen kantor depan serta harus disesuaikan dengan kebijakan hotel yang telah ditentukan sehingga terciptanya keselarasan antara tamu, karyawan dan pihak manajemen. $n t$.

\subsection{Pembahasan Hasil Penelitian}

Menurut Collier (2012) strategi penanganan keluhan dapat menggunakan metode ILEAD yaitu Identify, Listen, Empathize, Apologize dan Decide

1. Identify

Mencoba untuk mempengaruhi pengalaman tamu mengidentifikasi keluhan tamu. Hal tersebut dapat dilakukan dengan memahami postur dan bahasa tubuh serta ekspresi wajah tamu.

2. Listen

Setelah mengindentifikasi tamu yang kurang senang, maka selanjutnya dengarkan dengan baik keluhan yang disampaikan oleh tamu dan jangan membicarakan tamu, 
JMPP, Vol 3 No 1, April 2020

p-ISSN: 2654-9719

gelisah, dan membuat bahasa tubuh lainnya yang dapat ditafsirkan sebagai depensif atau rasa ketidakpedulian terhadap tamu.

3. Empathize

Kenali kekecewaan dan mencoba memahami apa yang dirasakan oleh tamu. Sedikit rasa empati mampu meredakan tamu yang merasa sangat kesal.

4. Apologize

Meminta maaf kepada tamu. Salah satu kalimat yang dapat diungkapkan yaitu "saya sangat menyesal mengalami ini"

5. Decide

Lakukan tindakan yang dapat mengatasi masalah dan memuaskan tamu tersebut.

\section{Penutup}

\subsection{Kesimpulan}

Berdasarkan dari hasil penelitian melalui observasi, wawancara, dokumentasi, maka dapat disimpulkan bahwa faktor-faktor yang mempengaruhi munculnya keluhan tamu adalah faktor internal dan eksternal yang meliputi fasilitas serta pelayanan. Terdapat 3 jenis keluhan tamu pada bagian kantor depan, hotel holiday inn resort baruna bali yaitu keluhan terhadap fasilitas, staf dan pelayanan. Keluhan tersebut disampaikan secara lisan dan tertulis. Untuk menangani keluhan tersebut karyawan kantor depan, hotel holiday inn resort baruna bali, menggunakan strategi penanganan keluhan yaitu metode ILEAD. Metode tersebut meliputi:

1. Identify yaitu mengindentifikasi permasalahan yang berkaitan dengan faktor-faktor penyebab munculnya keluhan dari tamu tersebut.

2. Listen yaitu mendengarkan dengan seksama atas hal-hal yang dikeluhkan oleh tamu tersebut dan mencari inti dari permasalahan

3. Empathize yaitu memunculkan sikap empati kepada tamu agar dapat memahami apa yang dirasakan oleh tamu tersebut

4. Apologize yaitu mengajukan permohonan maaf kepada tamu atas ketidaknyamanan yang dirasakan oleh tamu

5. Deliver Solution yaitu memberikan solusi terhadap masalah yang dialami oleh tamu

\subsection{Saran}

Dari penelitian diatas, peneliti dapat memberikan saran terkait Strategi Penanganan Keluhan, agar terciptanya keselarasan antara tamu dengan karyawan Front Office khususnya.

1. Bagi Karyawan Kantor Depan

Diharapkan karyawan kantor depan mampu untuk mengoptimalkan penanganan 
JMPP, Vol 3 No 1, April 2020

p-ISSN: 2654-9719

keluhan sesuai dengan standar operasional prosedur dan dapat mengkaji secara teliti faktor-faktor penyebab keluhan dari tamu.

2. Bagi Peneliti Selanjutnya

Diharapkan kepada peneliti selanjutnya agar mampu memberikan penjelasan yang maksimal dan mampu memberikan solusi atas permasalahn yang diangkat.

\section{Daftar Pustaka}

Bell, Simon J dan Luddington, James A. 2006. Coping With Customer Complaints. Journal of Service Research

Chaniago, S.A. 2014. Perumusan Manajemen Strategi Pemberdayaan Zakat. Pekalongan: Jurnal Hukum Islam, Volume 12 No. 1.

Collier, Larry, E. 2012. A Key To Simple Customer Service. Tersedia https://hidevelopmentinfo.wordpress.com/2012/04/27/a-key-to-simple-customer service/. (diakses pada tanggal 18 Juni 2020)

Kalebos, Fatmawati. 2016. Faktor-Faktor Yang Mempengaruhi Kepuasan Wisatawan yang Berkunjung Ke Daerah Wisata Kepulauan. Edisi Khusus. Jurnal Riset Bisnis dan Manajemen Volume 4 , No.3.

Kisti, R.M \& Mayasari, C.U. 2019. Upaya Kantor Depan Dalam Meminimalisir Keluhan Tamu di Hotel Cavinton Yogyakarta. Journal of Tourism and Economic, Volume 2, No.2.

Sitanggang, A.C. 2017. Pengaruh Penanganan Keluhan Pada Kepuasan Konsumen di Hotel Grand Praba Bandar Lampung. Bandar Lampung: Universitas Lampung.

Surjani, R. P. 2003. Manajemen Strategi dalam Menghadapi Era Globalisasi. Jurnal Unitas, Volume 11 No. 1.

Tarigan, O. Z. 2018. Strategi Komunikasi Customer Care Officer dalam Menangani Keluhan Pelanggan. Medan: Universitas Sumatra Utara. 